\title{
Who gets the jobs? Factors influencing the employability of property and construction graduates in the UK
}

Article

Accepted Version

Devaney, S. and Roberts, D. (2012) Who gets the jobs?

Factors influencing the employability of property and construction graduates in the UK. Construction Management and Economics, 30 (3). pp. 233-246. ISSN 0144-6193 doi: https://doi.org/10.1080/01446193.2011.654233 Available at https://centaur.reading.ac.uk/29408/

It is advisable to refer to the publisher's version if you intend to cite from the work. See Guidance on citing.

Published version at: http://www.tandfonline.com/doi/abs/10.1080/01446193.2011.654233

To link to this article DOI: http://dx.doi.org/10.1080/01446193.2011.654233

Publisher: Taylor \& Francis

All outputs in CentAUR are protected by Intellectual Property Rights law, including copyright law. Copyright and IPR is retained by the creators or other copyright holders. Terms and conditions for use of this material are defined in the End User Agreement.

www.reading.ac.uk/centaur 
Central Archive at the University of Reading

Reading's research outputs online 


\section{Who gets the jobs? Factors influencing the employability of property and construction graduates in the UK}

\section{Steven Devaney* and Deb Roberts}

University of Aberdeen Business School, Edward Wright Building,

Dunbar Street,

Aberdeen,

AB24 3QY,

United Kingdom

$*$ = corresponding author

This is an Accepted Manuscript of an article published by Taylor \& Francis in Construction Management and Economics on 27/02/2012, available online:

http://www.tandfonline.com/10.1080/01446193.2011.654233

\section{Acknowledgements}

The authors acknowledge the support of RICS Scotland for the initial research project from which this paper was developed. They would also like to thank HESA for the provision of data, Dr Sarah Jewell for initial guidance, and feedback from attendees at the 2011 COBRA conference on an earlier version of the paper. Finally, the paper has benefitted from the comments of the editor and anonymous referees. The usual disclaimer applies. 


\title{
Who gets the jobs? Factors influencing the employability of property and construction graduates in the UK
}

\begin{abstract}
Against a background of a strongly performing property market, the last decade saw a significant rise in entrants to undergraduate and postgraduate built environment programmes in the UK. The growth in postgraduate numbers reflected the emergence of conversion programmes with the result that, across a range of built environment pathways, employers can choose between different types of graduates: those straight from an undergraduate degree, those who have completed an additional postgraduate course or those who have taken, following a first degree in another discipline, a conversion programme in property or construction at postgraduate level. The paper uses a bivariate probit modelling approach to explore whether having a postgraduate taught (PGT) qualification systematically improves the probability of finding graduate level employment. It considers different built environment programmes while controlling for other factors that may influence employment outcomes, including university type, mode of study, gender, ethnicity and age. The results suggest that a postgraduate degree in land and property management significantly increases the probability of gaining graduate level employment, but this is not so for construction, quantity surveying or building surveying. The paper concludes by relating the findings to the wider discussion on changes in UK Higher Education.
\end{abstract}

\section{Keywords}

Bivariate probit; Graduates; Higher education; Labour markets; Postgraduate degrees 


\section{Who gets the jobs? Factors influencing the employability of property and construction graduates in the UK}

\section{Introduction}

A major development in the education of students for the property and construction professions over the last decade has been the growth in postgraduate level education. This includes the creation of many postgraduate conversion programmes that enable graduates in other subjects to obtain, in a relatively short time, core knowledge and skills required for employment in these disciplines and for the subsequent workplace training needed to gain membership of a professional body. Such conversion degrees have proved extremely popular, attracting UK and overseas students, and have increased the supply of graduates, which had been in steady decline throughout the 1990s (Dainty and Edwards, 2003). Thus, employers can now choose between three types of graduates: those straight from an undergraduate programme, those who have completed an additional postgraduate course or those who have taken a postgraduate conversion course after a first degree in something else. Yet whilst this development is well known, there is a lack of evidence on the employment outcomes experienced by these different groups and whether graduates with a postgraduate taught (PGT) qualification are preferred to those that only hold a first degree in the same built environment discipline.

Anecdotal evidence suggests that graduates from conversion programmes are popular with employers (Ashworth, 2007; Benyon, 1999). However, it is possible that the value of a taught postgraduate qualification in the recruitment and selection process varies across built environment subject areas. Moreover, employer attitudes towards the different types of qualifications may have changed as the number of both 
undergraduates and postgraduates has increased over time. Such issues are important to explore, particularly given the recent market downturn and the changes to UK Higher Education funding (see Department for Business, Innovation and Skills, 2011). A better understanding of how the different types of qualification affect the employability of graduates could be used to help guide future programme provision and wider educational policy, ensuring that due attention is paid to issues of access to the property and construction professions.

Against this background, this paper assesses the employment outcomes of graduates within a quantitative framework, testing whether or not taught postgraduate degrees (whether conversion or extension in nature) offer an advantage over undergraduate degrees in different built environment disciplines and whether this advantage has changed over time. It utilises data collected by the UK Higher Education Statistics Agency (HESA) with their Destination of Leavers from Higher Education (DLHE) survey. The focus is on students qualifying from construction, building surveying, quantity surveying or land and property management programmes over the period $2005 / 06$ to 2008/09. The analysis thus covers both a period of economic growth and one of economic downturn. A bivariate probit modelling approach is adopted which allows for the fact that similar characteristics may affect both the probability of undertaking a taught postgraduate course and of gaining graduate level employment.

The remainder of the paper is structured as follows. The next section sets the rise of taught postgraduate courses in property and construction in the context of the general rise in postgraduate education within higher education in recent years. Some existing knowledge regarding employment outcomes is also noted before the following 
section describes the methods used to test such outcomes in this study. After this, the data used is outlined before a further section presents the results of the study. The paper concludes by discussing the implications of the research findings.

\section{Background Literature}

Postgraduate education in the UK has grown markedly over the last fifteen years. Between $1997 / 98$ and 2008/09, the number of enrolled postgraduates rose by $36 \%$ compared with a $27 \%$ rise in the undergraduate population (Smith et al., 2010). Particularly important has been the growth of taught masters programmes in this period, with their growth driven by international student enrolments, especially students from outside the European Union (Sastry, 2004; House, 2010). Built environment subjects are amongst those that have shared in this growth, although with a greater emphasis on expanding part time provision than some other areas (Sastry, 2004; Boorman and Ramsden, 2009).

Taught masters programmes can take various forms, but it is possible to broadly distinguish those that extend knowledge in a particular discipline from those that enable conversion to a discipline by non-cognate degree holders. In property and construction, examples of both can be found, but there has been notable growth in conversion programmes in recent years. This development has occurred in the wake of falling undergraduate numbers for these subjects through the 1990s at a time when overall numbers in UK higher education were increasing (Dainty and Edwards, 2003; Wilkinson and Hoxley, 2005). In fact, the creation of postgraduate conversion programmes was encouraged as part of educational reforms by the Royal Institution 
of Chartered Surveyors (RICS) that were announced in 1999 and which aimed to increase the number of high quality graduates entering the property and construction professions. $^{1}$

The growth in student numbers on RICS accredited courses since then has been well documented (e.g. Hoxley and Wilkinson, 2006; Key, 2010). ${ }^{2}$ Figures for new enrolments up to 2008/09, the end of the analysis period, are shown in Table 1. Undergraduate numbers have risen steadily from a low point in 2002/03, whilst postgraduate numbers have increased dramatically from less than 500 such entrants in $2001 / 02$ to over 5,000 by $2008 / 09$. The latter trend means that the majority of entrants to RICS accredited degree programmes are now postgraduates, although not all will necessarily enter property or construction, or become RICS qualified, postgraduation. These rises mostly occurred in the context of a strongly performing UK property market, but enrolments also increased in 2008/09 despite a downturn in the property and construction sectors. Subsequently, though, the number of enrolments to such degrees has declined.

\section{INSERT TABLE 1 HERE}

The rising proportion of graduates from postgraduate programmes has influenced the labour market for the property and construction professions in the UK. In particular, graduates from conversion programmes are stated by Ashworth (2007) to be popular with employers, whilst Hoxley and Wilkinson (2006) note positive responses from employers in building surveying. This is tempered by concerns over the reduced time in conversion programmes for delivery of technical knowledge (Birch et al., 2005). 
Nonetheless, these studies and press articles (e.g. Benyon, 1999) draw attention to a range of positive attributes that employers associate with postgraduates, including maturity, motivation, wider experience and awareness, ability to learn quickly and strong intellectual skills. Not only are they more qualified in a general sense than their undergraduate counterparts (i.e. regardless of first degree subject), the decision to continue education to postgraduate level suggests a strong commitment to the chosen subject and its associated career pathways.

Despite this, there is only limited data on whether the trends and qualities noted above translate into different outcomes for postgraduates in terms of obtaining employment. Research at the all subject level by HESA (2009) and House (2010) shows that, as a general category of graduates, postgraduates are more likely to be in full time paid work, more likely to be in managerial, professional or technical occupations and less likely to be unemployed at both 6 months and 3.5 years after graduation than those qualifying from a first degree. In addition, there is a salary premium for postgraduates relative to holders of a first degree only. Some data also exists at subject level, including for the aggregated category 'Architecture, Building \& Planning'. Statistics on employment outcomes for this group (e.g. in HESA, 2010) indicate similar patterns, as well as some advantages for graduates from part time programmes, perhaps reflecting that many such graduates will have gained more experience of work whilst studying part time, with some having been sponsored by an employer. However, the Architecture, Building \& Planning figures are problematic for analysing property and construction owing to their exclusion of most real estate degrees, whilst they include architecture for which postgraduate study is a required part of the path to professional status. 
As House (2010) notes, the benefits associated with a PGT qualification are likely to reflect not only the qualification level, but also the greater age and experience within postgraduate cohorts. This is consistent with Keep and James (2010) who stress the importance of an applicant's personal characteristics and soft skills in the recruitment and selection process, many of which are not well reflected in formal qualifications. Indeed the Confederation of British Industry (CBI) point to an 80:20 rule whereby employers only afford $20 \%$ of weighting in a recruitment decision to hard skills (as reflected in qualifications) and $80 \%$ to non-certified, generic skills (less well reflected by qualifications) (CBI, 2007). However, a PGT qualification may be indirectly important as a signalling or screening device for these softer skills prior to interview, especially where there is a surfeit of qualified applicants as has become the case during the recent economic downturn. Moreover, Keep and James (2010) note that different types of employers may place different relative weightings on qualifications and personal / soft skills while Westcott and Burnside (2006) note a difference in employer preferences with regard to level and mode of study of built environment students. It follows that, in the property and construction sectors, there may be different views on the skills and qualities captured by a PGT qualification relative to first degree, and that this will be apparent through the employment outcomes of these types of graduates.

There are other applicant characteristics that may also have a bearing on employment outcomes. With respect to undergraduate leavers in the UK, Elias et al. (1999) and Smith et al. (2000) have noted gender differences in outcomes, with more men unemployed and a higher proportion of those in employment working in graduate 
level occupations. Similar patterns are reported for postgraduate leavers by Artess et al. (2008) and both they and Elias et al. find salary differences in favour of male graduates. The reasons for these patterns (including roles played by discrimination, choice and societal and cultural influences) are complex, varied and lie outside the scope of this paper, but they have received attention from other studies that examine employment in the surveying profession (Ellison, 1999) or construction industry (e.g. Dainty et al., 2000; Fielden et al., 2000). These studies consider a variety of career stages and not just the transition from education to employment, but their findings indicate that gender affects both recruitment and progression. This suggests that it should be controlled for when analysing the influence of different qualifications on employment outcomes.

Elias et al. (1999) and Artess et al. (2008) also explore the influence of other characteristics such as ethnicity, social class and age. Their research at the all subject level indicates that white graduates and older graduates have better employment outcomes. Within built environment research, the issues of ethnicity and diversity within the workforce have generated a number of recent studies that are reviewed by Caplan et al. (2009). This report notes a marked difference between relatively high representation of minority ethnic groups on built environment programmes in further and higher education and low representation in professional and managerial roles in these areas. They highlight several issues that impact the transition to employment, including difficulties for these groups in gaining work placements and interviews, informal recruitment practices that advantage groups with existing networks (white graduates) and biases in the recruitment process itself (see also Caplan and Gilham, 2005). Therefore, it is necessary to control for other personal characteristics, where 
possible, whilst other research indicates that the type of university attended may also influence graduate prospects (Artess et al., 2008; Urwin and Di Pietro, 2005).

In summary, whilst one might expect better employment outcomes for postgraduates given the greater investment by these students in their education, most evidence is at an aggregate level and may not hold for the property and construction sectors, where many postgraduates are from conversion programmes. Furthermore, a range of other factors that might have affected the labour market outcomes of these graduates are not controlled for in published statistics. It is these issues that the analysis here seeks to address by utilising individual level data on graduates from UK construction and property degrees at both undergraduate and postgraduate level.

\section{Methods}

The modelling approach adopted in this paper is based on the proposition that the probability of a graduate gaining graduate-level (as opposed to non-graduate level) employment is a function of type of qualification they hold. The paper focuses on the level of employment gained by graduates rather than the issue of their employment status (employed versus unemployed) for two reasons. First, from a theoretical perspective, it has been argued that the participation decision and hiring decision are jointly determined. In other words, the employment outcome for a particular type of graduate depends not only on the decision of employers to offer them the job but also the graduate's decision to enter the labour market (Mohanty, 2002). By focussing only on those who have entered employment by the time of data collection (around six months after graduation) this potential problem is overcome. Second, from a 
more pragmatic perspective, very few (less than 5 percent) of the sample of built environment graduates (described further below) were unemployed as opposed to undertaking further study or unavailable for employment. This would limit the robustness of an analysis of employment status rather than employment level, particularly if the intention is to try and ascertain differences between built environment programmes.

Therefore, the analysis follows the approach adopted by Smith et al. (2000) and focuses on the conditional probability of a graduate being in a graduate-level occupation given that the graduate has entered the labour market. In particular, the key research question is whether students graduating from a taught postgraduate programme have a higher probability of gaining graduate-level employment than those from an undergraduate degree programme after controlling for other individual characteristics and macroeconomic conditions that may influence employment outcomes.

Based on this, a standard univariate probit model of the effect of a postgraduate qualification on graduate employment is given as:

$$
G_{i}^{*}=\beta_{1} X_{i}+\beta_{2} W_{i}+\delta P G T_{i}+\varepsilon_{1 i}
$$

where $G_{i}^{*}$ is a latent variable denoting the probability of getting graduate level employment, $X_{i}$ are personal characteristics affecting that probability, $\mathrm{W}_{\mathrm{i}}$ are labour market factors and $\mathrm{PGT}_{\mathrm{i}}$ indicates whether or not the individual has a taught postgraduate qualification. In this model, $\varepsilon_{1 i}$ is taken as a normally distributed error 
term with a mean of zero and a variance of one that captures all of the unobserved determinants of the probability of gaining graduate-level employment.

The determinants of a having a PGT qualification could also be estimated using a univariate probit model as follows:

$P G T_{i}^{*}=\beta_{1} X_{i}+\beta_{2} W_{i}+v_{1 i}$

where $P G T_{i}^{*}$ is a latent variable denoting the probability of having a postgraduate degree and $X_{i}$ and $W_{i}$ are as defined above. $v_{1 i}$ is also taken as a normally distributed error term with mean zero and variance one, in this case capturing the unobserved determinants of the probability of having a postgraduate taught qualification.

If there is an overlap between the unobserved characteristics that determine the probability of getting a graduate-level job and that of having a PGT qualification, a univariate modelling approach such as that represented by equation (1) will produce biased results (Greene, 2000). In particular, the unobserved heterogeneity could result in $\varepsilon_{1 i}$ from equation (1) being correlated with the variables that explain PGT qualification. This means that the PGT variable is not exogenous to $G_{i}^{*}$ resulting in a biased coefficient on this variable.

A priori, there are various personal characteristics, some of which can be observed, that might jointly influence the probabilities of securing graduate level employment and of holding a postgraduate degree. For example, Keep and James (2010) note 
several studies which have found that, where there is a surfeit of qualified applicants, the recruitment decision comes to rest on attributes of the candidates that are classrelated (appearance, social capital, soft and generic skills) whilst Wakeling (2005) finds evidence that there is a social class differential in progression to postgraduate study. Thus, making allowance for the potential dependence in the two outcomes is important.

Correcting for this endogeneity could be done using an instrumental variable (IV) approach, but there are potential shortcomings of this approach (see Greene 1998, 2000). Instead, the approach adopted in this paper follows that suggested by Greene (1998) and the following simultaneous recursive bivariate probit model was estimated:

$$
\begin{aligned}
& G_{i}^{*}=\beta_{1} X_{i}+\beta_{2} W_{i}+\beta_{3} Z_{i}+\delta P G T_{i}+\varepsilon_{1 i} \\
& P G T_{i}^{*}=\beta_{1} X_{i}+\beta_{2} W_{i}+v_{1 i}
\end{aligned}
$$

The error terms $\varepsilon_{1 i}$ and $v_{1 i}$ are jointly distributed as bivariate normal with means of zero, variance of one and correlation $\rho . Z_{i}$ are factors that explain the probability of getting one of the endogenous variables (graduate level employment), but not the probability of having the other (PGT qualification). A key test for the bivariate model is whether the null hypothesis $(\rho=0)$ is rejected. Failure to reject this hypothesis means that the univariate probit model has consistent estimators. If $\rho$ is found to be significantly different from zero and positive, then some of the unobserved factors increase both the probability of gaining graduate level employment and of having a postgraduate degree, and this would lead to an 
overestimation of the effect of a PGT qualification on graduate employment in the univariate model. Alternatively, if $\rho$ is significantly different from zero and negative, then the estimated effect of PGT qualification on graduate employment from a univariate model would be underestimated. The variables that comprise vectors $X, W$ and $Z$ are explained below.

\section{Data and model variables}

Analysis is based on a sample of 12,580 graduates from four types of built environment programmes included in the HESA Destination of Leavers from Higher Education (DLHE) dataset 2005/06 to 2008/09. This dataset is based on responses to a survey that is sent to all qualifiers from UK Higher Education institutions between 4 and 12 months after graduation, depending on their graduation date. This limited time window should be kept in mind when interpreting the findings. For academic year 2008/09, the survey was sent to 470,940 qualifiers in total and a response rate of 75.3\% was reported (HESA, 2010).

The dataset contains information on the subject and level of qualification studied, but it does not disclose the title of the programme on which respondents were registered. Instead, these are grouped into subject areas using a classification scheme called the Joint Academic Coding System (JACS). Previous research on construction education by Dainty and Edwards (2003) focused on the K2 category of JACS, which covers programmes in building and construction disciplines. In contrast, this paper also considers graduates from land and property management programmes that fall within the N2 category. However, in common with Dainty and Edwards, it excludes architecture and planning programmes which are often included within the wider 
definition of Built Environment education. These subject areas were excluded on the basis that they have their own distinct requirements in terms of the qualifications required for progression to professional status. Similarly, students graduating from either a postgraduate research degree or an "Other undergraduate" programme (which would lead to a qualification below degree level) were dropped from the analysis on the basis that they are unlikely to be competing for the same employment opportunities.

A key issue given the research question is the definition of graduate level employment. A number of previous studies including Chevalier and Lindley (2009) have used a classification developed by Elias and Purcell (2004) and which is applied here using the 3-digit Standard Occupational Classification (SOC) codes included in the HESA dataset. Elias \& Purcell's definition of graduate level jobs is based on the proportion of workers in a particular job who have a degree. By computing and comparing the proportions for two separate cohorts of workers (under $35 \mathrm{~s}$ and over 40s), it allows for changes in graduate-level occupations over time and also what the authors refer to as the "fragmentation of the labour market" that has occurred since the 1990s (Elias and Purcell, 2004; Chevalier and Lindley, 2009). For the purposes of analysis, the four separate types of graduate-level jobs defined by Elias and Purcell (traditional, modern, new and niche) were combined into a single category and contrasted with the non-graduate level occupations.

Based on this, Table 2 shows the distribution of responses across the two binary dependent variables for all property and construction graduates in the sample. As explained earlier, the 1,643 leavers not employed, but in "other activity" (including 
those undertaking further full time study, those assumed unemployed and those not available for employment) are excluded from the graduate employability analyses.

\section{INSERT TABLE 2 ABOUT HERE}

While the data collected by HESA covers a wide range of variables, not all were used in this study owing to missing observations, quality of data or lack of relevance to the research question. Table 3 indicates those categories of variables which were used in the analysis, with the nature of each further discussed below.

\section{INSERT TABLE 3 ABOUT HERE}

Gender, ethnicity and age group are included in both of the bivariate probit equations as previous research suggests that they influence the probability of gaining graduate level employment and of undertaking postgraduate study (e.g. Artess et al., 2008). These variables are denoted as $X_{i}$ variables in equations (3) and (4) above. Similarly mode of study (part time or full time) is included in both equations (and thus represents another $X_{i}$ variable) since part time study may be more strongly associated with a postgraduate route and may have a positive effect on getting graduate level employment. Meanwhile, during the four years covered by the data (2005/06 to 2008/09), the macro economy (and property market) moved from a period of boom to recession. It was felt that such major changes would affect not only the chances of a leaver gaining employment but also the probability of them undertaking a postgraduate programme. Hence, year dummies are used in both model equations to represent market conditions, that is $W_{i}$ in equations (3) and (4). 
There are two types of variables that are included in only the graduate employability model (represented by $Z_{i}$ in equation (3) above). University type is included on the understanding that employers may have preferences for graduates from certain types of institutions, but that this does not influence the probability of having a PGT qualification. To simplify analysis, the 209 institutions included in the DLHE dataset were grouped into two broad categories: "old universities" (including Oxbridge, Russell group, 1994 group and other old universities) and "new universities" (comprising post 92 universities and FE or HE colleges with degree-level programmes). Second, it was possible, for first degree graduates, to distinguish those leavers with good (first class or higher upper second class degrees) from those with moderate (lower second) or weaker (third or unclassified) academic performance.

Finally, to capture differences across built environment subjects, the JACS 4 digit subject variable was used to distinguish four categories of programmes as follows:

1. Construction - $\mathrm{K}(200)$ Building, $\mathrm{K}(210)$ Building Technology, $\mathrm{K}(220)$ Construction Management, $\mathrm{K}(250)$ Conservation of Buildings and $\mathrm{K}(290)$ Building not elsewhere classified);

2. Building Surveying - K(230);

3. Quantity Surveying - K(240);

4. Land and Property Management - N(230) Land and Property Management, N(231) Land Management, N(232) Property Management and N(234) Valuation and Auctioneering. 
As well as modelling all built environment programmes together, separate bivariate probit models were estimated for each of these categories. To provide a context for subsequent analysis, Table 4 reports, by subject, the proportion of leavers with each explanatory variable. The table only relates to those student leavers included in the subsequent analysis (that is, those in some type of employment approximately six months after graduation). It also shows proportions for type of employment gained (graduate or non-graduate level). However, the latter measure does not indicate whether employment was in that specific field, though research by Roberts et al. (2009) examining graduates in Scotland has documented a strong relationship between type of built environment programme studied and type of job obtained. ${ }^{3}$

\section{INSERT TABLE 4 ABOUT HERE}

Table 4 suggests some key differences between subjects. Land and property management has a higher proportion of females and graduates from old universities, and the highest proportion of taught postgraduate leavers. In contrast, there are few leavers with a PGT qualification in quantity surveying, but this subject has the highest proportion of students that studied part time. Construction and building surveying are more similar to one another, but there are a higher proportion of PGT leavers in the former. Finally, quantity surveying has the lowest proportion of leavers entering non-graduate level employment. This means that results relating to quantity surveying may be less robust than those for the other subject areas.

\section{Econometric Results}


Table 5 presents the bivariate probit results for all subject areas and compares them to estimates from an equivalent univariate probit analysis (where the probability of gaining graduate level employment and that of having a PGT qualification are estimated separately).

\section{INSERT TABLE 5 ABOUT HERE}

The estimate for $\rho$ in the bivariate model is 0.2328 and significantly different from zero at the $3 \%$ level. This suggests that a univariate model of graduate employment would overestimate the significance of a postgraduate qualification. Indeed, comparing the estimates across both versions shows that whilst in the univariate model, PGT positively and significantly increases the probability of gaining graduate level employment, once the endogeneity of the PGT variable is controlled for, the coefficient becomes insignificant. The results also indicate that having a good (first or upper second class) degree significantly increases the likelihood of gaining graduate employment relative to the omitted category of a lower second class degree, while having a third/unclassified degree significantly decreases the same likelihood. The land and property management subject dummy becomes insignificant in the bivariate model (as compared to negative significant in the univariate model). In other words, once the joint dependence of taking a PGT qualification and gaining graduate level employment is recognised, land and property students are no more likely to gain graduate employment than graduates from a building surveying programme (the omitted subject category). Otherwise, the coefficients on the other explanatory variables in the graduate employment equation are qualitatively similar across univariate and bivariate models and have the expected signs. 
Results relating to the year dummy variables are interesting, especially comparing across the graduate employment and postgraduate qualification equations. The sign and magnitude of estimated coefficients in the graduate employment equation are as expected given that, compared to the base year 2005/06, the economy grew in 2006/07 (year 2) and then entered a downturn in 2007/08 (year 3) which deepened in 2008/09 (year 4). Turning to the estimates in the postgraduate qualification equation, while the 2007/08 dummy is negative, suggesting an initial negative effect of the downturn on PGT admissions, the coefficient for the final year 2008/09 has a positive and significant coefficient suggesting that poor employment prospects may have increased demand for PGTs in property and construction subjects. This is somewhat counterintuitive. However it could reflect either a lack of alternative employment options or expectations of an upturn in the property market by the time that students graduate. Other coefficients in the PGT equation are of expected sign and are similar across both versions of the model.

To investigate the issue of changes over time in the value of a good first degree or PGT qualification for securing graduate level employment, an extended version of the bivariate probit model was estimated. This was identical to that shown in equation (3) except that it included degree type - year interaction variables. The inclusion of the extra interaction variables did not qualitatively change the results from those shown in Table 5. Indeed, the coefficient values for the original variables remained either identical or very similar to those given in the table. Therefore, rather than present the full results, Table 6 shows only the coefficients and standard errors for the new interaction variables. ${ }^{4}$ 


\section{INSERT TABLE 6 ABOUT HERE}

None of the degree class time interaction variables are significant. This suggests that neither the advantage of holding a good degree class or the disadvantage of having a weaker degree class relative to a lower second class degree changed from that in 2005/06, the base year. In contrast, there is evidence that holding a PGT qualification enhanced the probability of securing a graduate level job when the general economic environment entered a downturn (years 3 and 4 in the model).

Tables 7 and 8 display results for each individual built environment subject area. The model specifications are similar to those above expect that, in these cases, subject dummies are not required and the ethnicity variables are modified owing to the small number of observations in each category. Additional analysis (not reported) indicated that, as for the full model described above, degree class time interaction variables were not significant and did not qualitatively change the results. This is why only the PGT - year interactions are included in the models presented here.

\section{INSERT TABLE 7 ABOUT HERE}

In only one of the four models is $\rho$ significantly different from zero - the land and property management model. The sign of $\rho$ in this model is negative, which suggests that a univariate model would underestimate the importance of having a PGT qualification for graduate employability. It follows that, in the other three subject 
areas, a univariate probit model of graduate employment would provide consistent estimates.

The coefficients in Table 7 suggest that a PGT qualification only has a positive effect on the likelihood of obtaining a graduate level job for land and property management students. For the other disciplines, the coefficient is found to be not significantly different from zero. Meanwhile, non-white ethnicity appears to have a significant and negative impact on the likelihood of gaining a graduate level job in two of the four subjects after having controlled for the type of qualification held and other personal characteristics. Being over 24 is estimated to have a negative significant impact for land and property management leavers, but is positive for building surveying. Studying part-time is also significant and negative for land and property management, but positive and significant for the other subject groups, corresponding with preferences noted by Westcott and Burnside (2006).

The results relating to the year dummy variables suggest that the impact of the economic downturn on graduates from construction and building surveying programmes was more immediate and larger in magnitude than for the other two subject groups. In addition, there is evidence that having a PGT qualification in construction becomes more advantageous as the economy enters a downturn (years 3 and 4). In contrast, there is evidence of a slight decrease in the value of a PGT qualification in year $2(2006 / 07)$ compared to year $1(2005 / 06)$ for land and property management graduates. 
Finally, to check the robustness of the results in relation to the three subject areas where $\rho$ is not significantly different from zero, the results from the univariate version of the model are shown in Table 8 . These are qualitatively very similar across all variables to those in the bivariate model, as expected. However, the magnitude and significance of coefficients in the land and property management subject area are very different. In particular, if the fact that having a PGT qualification and securing a graduate level job are jointly dependent is ignored, the negative effect of being non-white is over estimated, the negative age effect is ignored, and the positive effects of holding a PGT qualification are underestimated.

\section{INSERT TABLE 8 ABOUT HERE}

\section{Conclusions}

Property and construction are subjects in which marked growth has occurred in the provision of postgraduate degrees, especially conversion degrees for graduates of other subjects. This paper provides evidence on the value of a postgraduate qualification in securing graduate level employment upon leaving university. Results from the estimations suggest that it has a positive effect on the likelihood of securing a graduate level job for land and property management. However, it appears to confer no significant advantages in the fields of construction, building surveying and quantity surveying. Meanwhile, other coefficients highlight differences between land and property management and the other subject groups, though, in all cases, a good first degree appears to be a positive factor and a weaker first degree result has a negative influence on employment outcomes. 
The finding that having a taught postgraduate degree confers no tangible employment benefits for construction, building surveying and quantity surveying was unexpected. In particular, as the number of graduates has increased over time, it was expected that a PGT qualification would be relied on more in the recruitment and selection process as an indicator, not just of technical skills, but of graduate attributes such as maturity, motivation and experience. It was also expected that the value of either a PGT qualification or good first degree class would increase as the economy entered recession and competition for jobs increased. However, this was only found to be the case for PGT qualifications in construction. Having said this, the results do show clearly the impacts of the recession on employment prospects for all graduates. Ongoing reductions in public expenditure on construction and infrastructure projects suggest that the job market for graduates will be continue to be difficult in the foreseeable future and so competition between graduates from different types of programme may well become more intense.

The findings have important implications for future programme provision and wider education policy. Until recently, postgraduate conversion programmes in built environment have provided a useful means of matching the supply of graduates to increasing industry demand without enduring the time lag associated with the completion of undergraduate programmes. The recent fall in demand for graduates associated with the economic downturn may reduce the attractiveness of such programmes for students and employers alike. In addition, proposed changes in higher education funding and the significant increase in undergraduate student fees in England and Wales (Department for Business, Innovation and Skills, 2011) give rise to further questions on whether postgraduate qualifications will remain popular. 
Evidence on whether previous increases in fees have deterred students from postgraduate study is mixed (Smith et al., 2010). However the larger fee increases being introduced in parts of the UK from 2012/13 mean that, in future, postgraduate programmes will have to demonstrate clear employability benefits in order to attract students. In the case of real estate programmes, where the employment advantages for postgraduates appear to be stronger, the future of the postgraduate route is more unclear, depending on how both universities and potential (undergraduate and postgraduate) students respond to the new funding environment.

The findings have a number of implications for industry. First, the increase in the range of qualifications in built environment education means that the transition of new graduate employee to professional, accredited status will follow a greater diversity of paths than was the case under a system where most entrants to the profession came from undergraduate programmes. This, in turn, may require industry to have a more nuanced approach to post graduation, workplace training. More generally, the results in relation to gender and ethnicity variables add to the debate in the UK on access to the professions (see, for example, Panel on Fair Access to the Professions, 2009). Whilst these variables were used primarily as controls in this analysis, the results suggest that access continues to be an issue for women in construction and for non-white ethnic groups in construction and building surveying. In contrast, being older appears to be an advantage in some built environment areas, but not in others. The existence of bias in recruitment outcomes suggested by these results is worthy of further investigation. Similarly, the associated issue of access on to built environment programmes (undergraduate and postgraduate) is worthy of more attention, although this would require an alternative dataset. 
The research has several limitations, particularly in terms of the definition of graduate level job, which does not necessarily indicate employment in either the property or construction industries. In the current paper, all types of graduate level occupations (traditional, new, modern and niche) are conflated and no attention is given to the possibility of differences in occupation type by qualification or, linked to this, whether there are differences in the salaries earned by different types of graduate. Thus, further analysis to reliably determine relevant industry employment and salary levels would be valuable, though this would require access to an alternative dataset as the HESA dataset used has limitations, particularly in relation to the salary levels of graduates. Another limitation of the HESA dataset and the current analysis is the inability to differentiate postgraduate conversion programmes from programmes that extend knowledge in a particular subject. Such differences may underlie some of the subject-specific findings in the paper and are thus worthy of further analysis.

Beyond differences in the type of postgraduate qualifications available, an implicit assumption in the analysis is that the nature of the qualifications remains constant over the period analysed. Interactions between HE establishments and employers and the increasing focus of universities on attracting overseas students are both likely to have influenced the nature of PGT qualifications over time. However, it is assumed that any significant changes in the nature of programmes will have occurred before the start of analysis, 2005/06, and that changes over the four year period to 2008/09 are limited. Nonetheless, given the international nature of many postgraduate programmes in property and construction, the analysis could be extended to consider 
whether the value of alternative UK built environment qualifications in overseas employment markets has changed over time. In addition, it may be possible to apply the methods used here in non-UK contexts, if appropriate data are available.

Previous experience suggests that economic downturns can lead to both a loss of built environment graduates to other industries (due to a lack of employment opportunities in their subject area) and a reduction in enrolments onto built environment programmes. This, in turn can give rise to future shortages of graduates. While this paper provides some new evidence on higher education and labour market outcomes in the property and construction industries, further research on the interdependency between the various types of degree qualifications and macroeconomic conditions would be timely.

\section{Acknowledgements}

INSERT AFTER REVIEW

\section{Endnotes}

1. Information on the proportion of postgraduates enrolled on conversion and extension programmes in property and construction is not available.

2. The use of figures from the Royal Institution of Chartered Surveyors (RICS) reflects data availability. The RICS are reported as accrediting $25.3 \%$ of UK 
undergraduate degrees in property and construction, narrowly ahead of the Chartered Institute of Building (CIOB) on 24\% (Williams et al., 2011: 56).

3. This project used both HESA and RICS graduate employment data for the period 2002/03 to 2006/07. The RICS data enabled more detailed matching between programme studied, job title and employer; using this, it was found that $72 \%$ of graduates from building surveying degrees gained employment in building surveying roles and $72 \%$ from construction and quantity surveying degrees were hired in either construction or quantity surveying posts.

4. Full estimation results from the extended version of the model are available from the authors on request.

\section{References}

Artess, J., Ball, C. and Mok, P. (2008) Higher Degrees: Postgraduate Study in the UK 2000/01 to 2005/06. DIUS Research Report 08-16, Department for Innovation, Universities and Skills.

Ashworth, A. (2007) Resourcing programmes in the built environment. Report for the Council of Heads of Built Environment Departments, Centre for Education in the Built Environment.

Benyon, L. (1999) University Challenge. Property Week, 20 August 1999.

Birch, A., Warren, C. and Westcott, T. (2005) Course provision in building and quantity surveying for non-cognate graduates. Paper presented at the RICS COBRA conference, Brisbane, 3-5 July.

Boorman, S. and Ramsden, B. (2009) Taught postgraduate students: market trends and opportunities. Universities UK. 
Caplan, A., Aujla, A., Prosser, S. and Jackson, J. (2009) Race Discrimination in the Construction Industry: A Thematic Review. Research Report 23, Equality and Human Rights Commission, Manchester.

Caplan, A. S. and Gilham, J. (2005) Included against the odds: failure and success among minority ethnic built-environment professionals in Britain. Construction Management and Economics, 23 (10), 1007-1015.

Chevalier, A. and Lindley, J. (2009) Overeducation and the skills of UK graduates. Journal of the Royal Statistical Society A, 172 (2), 307-337.

CBI (2007) Shaping up for the Future - The Business Vision for Education and Skills. Confederation of British Industry, London.

Dainty, A. R. J., Bagilhole, B. M. and Neale, R. H. (2000) A grounded theory of women's career under-achievement in large UK construction companies. Construction Management and Economics, 18 (2), 239-250.

Dainty, A. R. J. and Edwards, D. J. (2003) The UK building education recruitment crisis: a call for action. Construction Management and Economics, 21 (7), 767775.

Department for Business, Innovation and Skills (2011) Higher Education: Students at the Heart of the System. Cm 8122, The Stationery Office, London.

Elias, P., McKnight, A., Pitcher, J., Purcell, K. and Simm, C. (1999) Moving On: Graduate Careers Three Years After Graduation. Careers Service Unit / Department for Education and Employment, Manchester.

Elias, P. and Purcell, K. (2004). SOC (HE): A classification of occupations for studying the graduate labour market. Research Paper No. 6, Researching Graduate Careers Seven Years On. ESRU and Warwick Institute for Employment Research. 
Ellison, L. (1999) Surveying the Glass Ceiling: An Investigation of the Progress Made by Women in the Surveying Profession. RICS Research, London.

Fielden, S. L., Davidson, M. J., Gale, A. W. and Davey, C. L. (2000) Women in construction: the untapped resource. Construction Management and Economics, $18(1), 113-121$.

Greene, W. H. (1998) Gender economics courses in Liberal Arts Colleges: Further results. Journal of Economic Education, 29 (4), 291-300.

Greene, W. H. (2000) Econometric Analysis. Fourth Edition, Prentice Hall, London.

HESA (2009) Destinations of Leavers from Higher Education Institutions: Longitudinal Survey of the 2004/05 cohort. Higher Education Statistics Agency, Cheltenham.

HESA (2010) Destinations of Leavers from Higher Education Institutions: 2008/09. Higher Education Statistics Agency, Cheltenham.

House, G. (2010) Postgraduate Education in the United Kingdom. Higher Education Policy Institute and The British Library.

Hoxley, M. and Wilkinson, S. (2006) The employers' perspective of the impact of RICS education reform on building surveying. Structural Survey, 24 (5), 405411.

Keep, E. and James, S. (2010) Recruitment and Selection - the Great Neglected Topic. SKOPE Research Paper No. 88, SKOPE, Cardiff University \& SKOPE, University of Oxford.

Key, T. (2010) The Future of Real Estate Education, in Newell, G. and Sieracki, K. (eds) Global Trends in Real Estate Finance, Wiley-Blackwell, Chichester, pp. 262-277. 
Mohanty, M. S. (2002) A bivariate probit approach to the determination of employment: a study of teen employment differentials in Los Angeles County. Applied Economics, 34 (2), 143-156.

Panel on Fair Access to the Professions (2009) Unleashing Aspiration: The Final Report of the Panel on Fair Access to the Professions. July 2009, Cabinet Office, London.

Roberts, D., Devaney, S., Findlay, N., Laing, R. and Buda, G. (2009) The Future of Built Environment Higher Education in Scotland. Report to RICS Scotland.

Sastry, T. (2004) Postgraduate Education in the United Kingdom. Higher Education Policy Institute.

Smith, A., Bradshaw, T., Burnett, K., Docherty, D., Purcell, W. and Worthington, S. (2010) One Step Beyond: Making the most of postgraduate education. Research Report 10/704, Department for Business, Innovation and Skills.

Smith, J., McKnight, A. and Naylor, R. (2000) Graduate employability: Policy and performance in Higher Education in the UK. The Economic Journal, 110 (464), pp. 382-411.

Urwin, P. and Di Pietro, G. (2005) The impact of research and teaching quality inputs on the employment outcomes of postgraduates. Higher Education Quarterly, 59 (4), 275-295.

Wakeling, P. (2005) La noblesse d'état anglaise? Social class and progression to postgraduate study. British Journal of Sociology of Education, 26 (4), 505-522.

Westcott, T. and Burnside, K. (2006) Part-time Education for Property and Construction Surveyors. Paper presented at the RICS COBRA conference, University College London, 7-8 September. 
Wilkinson, S. and Hoxley, M. (2005) The impact of RICS education reform on building surveying. Structural Survey, 23 (5), 359-370.

Williams, A., Galloway, K. and Mullin, P. (2011) Built Environment Higher Education: State of the Nation. Centre for Education in the Built Environment, University of Salford. 
Table 1: Entrants to RICS accredited programmes in the UK - 2000/1 to 2008/9

\begin{tabular}{lrrrrrrrrr}
\hline & $2000 / 1$ & $2001 / 2$ & $2002 / 3$ & $2003 / 4$ & $2004 / 5$ & $2005 / 6$ & $2006 / 7$ & $2007 / 8$ & $2008 / 9$ \\
\hline Undergraduate & 2,949 & 2,572 & 2,554 & 2,721 & 3,083 & 3,690 & 3,727 & 4,031 & 4,295 \\
Postgraduate & 419 & 1,363 & 1,805 & 2,310 & 2,929 & 3,627 & 4,697 & 4,747 & 5,489 \\
TOTAL & 3,368 & 3,935 & 4,359 & 5,031 & 6,012 & 7,317 & 8,424 & 8,778 & 9,784 \\
\% Postgraduate & $12 \%$ & $35 \%$ & $41 \%$ & $46 \%$ & $49 \%$ & $50 \%$ & $56 \%$ & $54 \%$ & $56 \%$ \\
\hline
\end{tabular}

Source: RICS Education and Qualification Standards

Table 2: Employment type by qualification level

\begin{tabular}{lrrrr}
\hline & \multicolumn{2}{c}{ Type of employment } & & \\
\cline { 2 - 4 } & $\begin{array}{c}\text { Non- } \\
\text { graduate } \\
\text { level }\end{array}$ & $\begin{array}{c}\text { Graduate } \\
\text { level }\end{array}$ & $\begin{array}{c}\text { Other } \\
\text { activity }\end{array}$ & Total \\
\hline First degree & 1,080 & 7,103 & 1,401 & 9,584 \\
Taught postgraduate degree & 327 & 2,427 & 242 & 2,996 \\
\hline Total & 1,407 & 9,530 & 1,643 & 12,580 \\
\hline
\end{tabular}

Table 3: Variables used in the bivariate probit model

\begin{tabular}{lcc}
\hline \multirow{2}{*}{ Variable } & \multicolumn{2}{c}{ Equation } \\
\cline { 2 - 3 } Standard occupational classification (3-digit level) & $\begin{array}{c}\text { Graduate-level } \\
\text { employment }\end{array}$ & PGT qualification \\
Qualification level & $\begin{array}{c}\text { (for defining dependent } \\
\text { binary variable) }\end{array}$ & $\begin{array}{c}\text { (PGT is dependent } \\
\text { binary variable) }\end{array}$ \\
\hline$X_{i}$ (Personal characteristics) & & $\mathrm{X}$ \\
Gender & $\mathrm{X}$ & $\mathrm{X}$ \\
Ethnicity & $\mathrm{X}$ & $\mathrm{X}$ \\
Age group & $\mathrm{X}$ & $\mathrm{X}$ \\
Mode of study & $\mathrm{X}$ & $\mathrm{X}$ \\
Programme type (at JACS 4 digit level) & $\mathrm{X}$ & \\
\hline$W_{i}$ (Labour market conditions) & $\mathrm{X}$ & \\
Year of graduation & $\mathrm{X}$ & \\
\hline$Z_{i}$ variables: & $\mathrm{X}$ & \\
$\quad$ University type & & \\
Degree Class (UG degree) or PGT & & \\
\hline
\end{tabular}


Table 4: Proportion of each characteristic by subject area

\begin{tabular}{|c|c|c|c|c|}
\hline Observations & $\begin{array}{c}\text { Construction } \\
n=5,539\end{array}$ & $\begin{array}{c}\text { Building } \\
\text { surveying } \\
n=1,836\end{array}$ & $\begin{array}{c}\text { Quantity } \\
\text { surveying } \\
n=1,927\end{array}$ & $\begin{array}{c}\text { Land \& } \\
\text { property } \\
\text { management } \\
n=1,635\end{array}$ \\
\hline Grad. level employment & 0.864 & 0.855 & 0.948 & 0.823 \\
\hline Non-grad. level employment & 0.136 & 0.145 & 0.052 & 0.177 \\
\hline \multicolumn{5}{|l|}{$X_{i}$ (Personal characteristics) } \\
\hline Female & 0.164 & 0.167 & 0.144 & 0.317 \\
\hline Male & 0.836 & 0.833 & 0.856 & 0.683 \\
\hline Black & 0.020 & 0.021 & 0.024 & 0.019 \\
\hline White & 0.845 & 0.887 & 0.851 & 0.850 \\
\hline Asian & 0.044 & 0.039 & 0.039 & 0.046 \\
\hline Other ethnic group & 0.014 & 0.016 & 0.012 & 0.016 \\
\hline Unknown ethnicity & 0.042 & 0.020 & 0.026 & 0.029 \\
\hline Non UK domicile $^{1}$ & 0.034 & 0.017 & 0.050 & 0.038 \\
\hline Under 24 years & 0.531 & 0.516 & 0.579 & 0.552 \\
\hline Over 24 years & 0.469 & 0.484 & 0.421 & 0.448 \\
\hline Part time study & 0.448 & 0.354 & 0.571 & 0.243 \\
\hline Full tme study & 0.552 & 0.646 & 0.429 & 0.757 \\
\hline \multicolumn{5}{|c|}{$W_{i}$ (Labour market conditions) } \\
\hline Year of graduation 2005/6 & 0.237 & 0.206 & 0.217 & 0.290 \\
\hline Year of graduation 2006/7 & 0.238 & 0.247 & 0.235 & 0.275 \\
\hline Year of graduation 2007/8 & 0.244 & 0.248 & 0.241 & 0.219 \\
\hline Year of graduation 2008/9 & 0.280 & 0.299 & 0.307 & 0.216 \\
\hline \multicolumn{5}{|l|}{$Z_{i}$ variables: } \\
\hline Old university & 0.266 & 0.175 & 0.223 & 0.604 \\
\hline New University & 0.734 & 0.734 & 0.734 & 0.734 \\
\hline Good UG degree class ${ }^{2}$ & 0.472 & 0.565 & 0.538 & 0.232 \\
\hline Medium UG degree class ${ }^{2}$ & 0.233 & 0.229 & 0.321 & 0.119 \\
\hline Low UG degree class ${ }^{2}$ & 0.071 & 0.032 & 0.062 & 0.019 \\
\hline PGT degree & 0.223 & 0.173 & 0.088 & 0.629 \\
\hline
\end{tabular}

Notes:

${ }^{1}$ HESA do not collect information on the ethnic background of non UK domicile graduates. As a result, these are treated as a separate category.

${ }^{2}$ Degree class is only available for those graduating with an undergraduate (first degree). As a consequence, the proportions sum to one when those graduating with a PGT degree in the subject area are included. 
Table 5: Results from bivariate and univariate probit models: Aggregate subject area

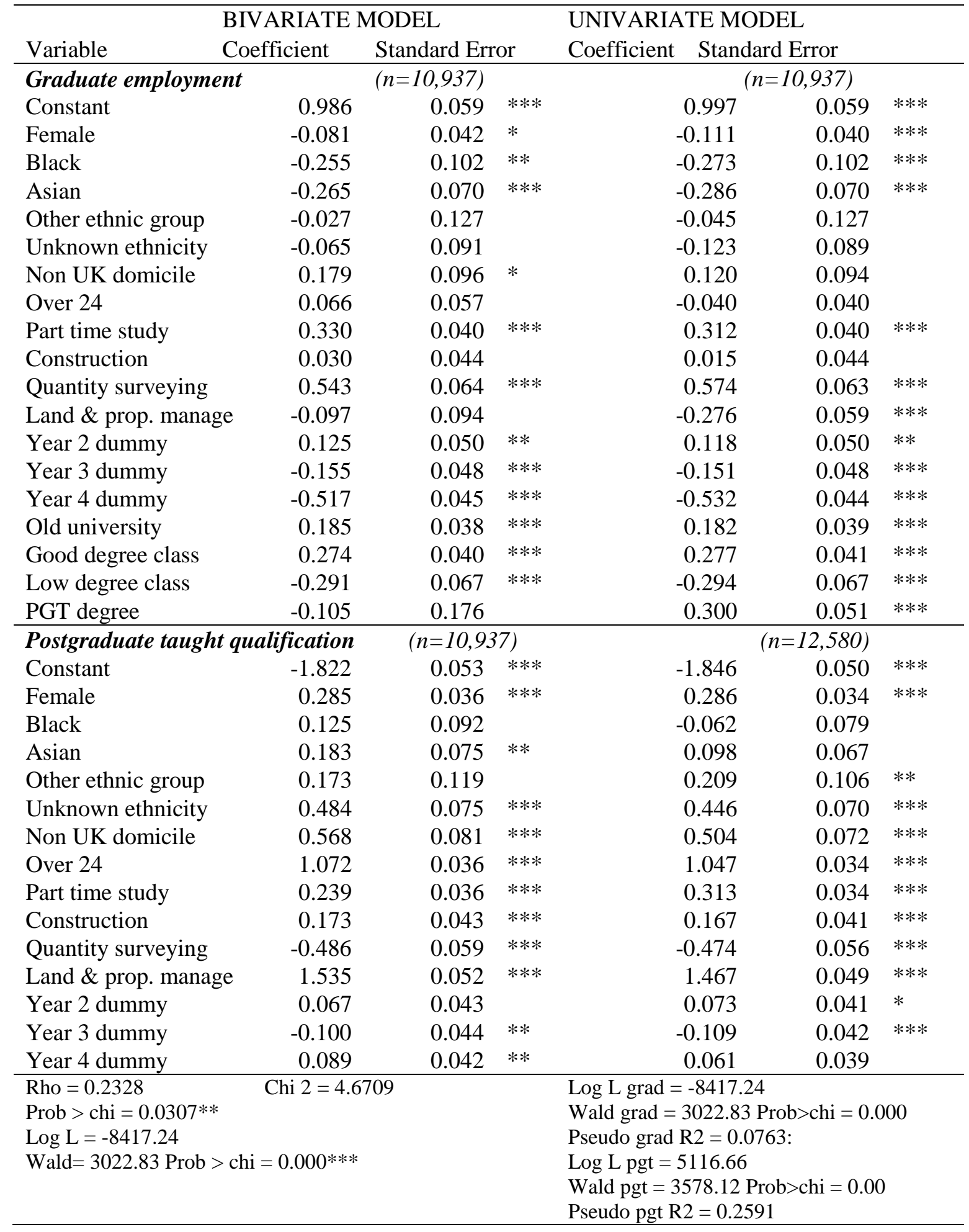

Notes: $* * *, * *$ and $*$ denote $1 \%, 5 \%$ and $10 \%$ significance levels, respectively. Omitted categories are white, under 24 , full time study, new university and graduating with a lower second class degree. The omitted subject category is building surveying. 
Table 6: Selected results from the extended bivariate model with year interaction variables

\begin{tabular}{lrc}
\hline & Coefficient & Standard \\
& -0.185 & 0.129 \\
\hline Good degree_y2 interaction & 0.065 & 0.119 \\
Good degree_y3 interaction & 0.085 & 0.112 \\
Good degree_y4 interaction & -0.114 & 0.192 \\
Low degree_y2 interaction & -0.012 & 0.189 \\
Low degree_y3 interaction & 0.148 & 0.182 \\
Low degree_y4 interaction & -0.104 & $0.135 \quad * * *$ \\
PGT_yr2 interaction & 0.360 & $0.135 \quad * * *$ \\
PGT_yr3 interaction & 0.212 & $0.120 \quad *$ \\
PGT_yr4 interaction & &
\end{tabular}

Notes: $* * *, * *$ and $*$ denote $1 \%, 5 \%$ and $10 \%$ significance levels, respectively. Coefficients for all other dependent variables were the same or close to those shown in Table 5. 
Table 7: Results from the bivariate probit models by subject area

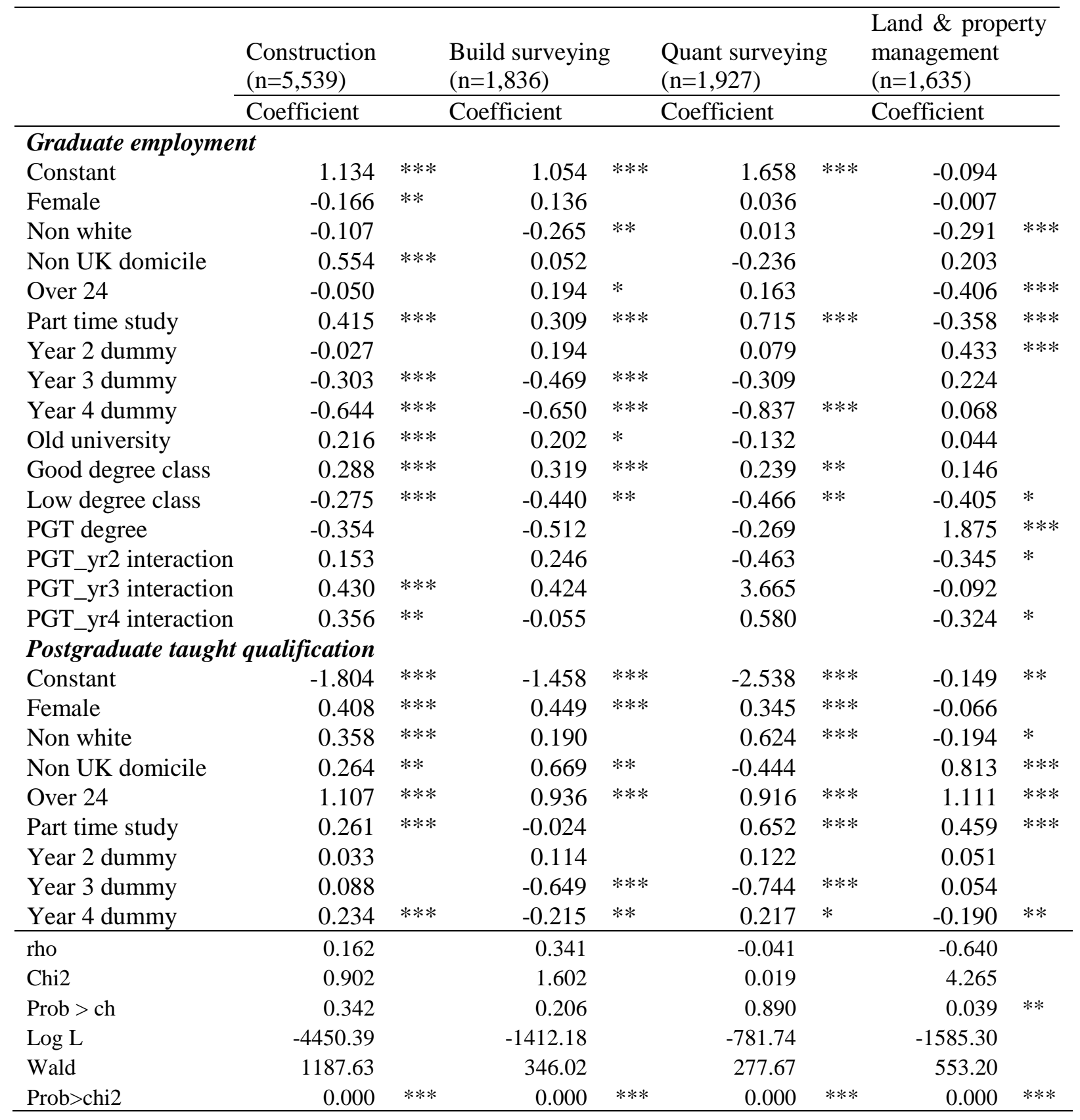

Notes: $* * *, * *$ and $*$ denote $1 \%, 5 \%$ and $10 \%$ significance levels, respectively. Omitted categories are white, under 24 , full time study, new university and graduating with a lower second class degree. 
Table 8: Results from the univariate graduate employment models by subject area

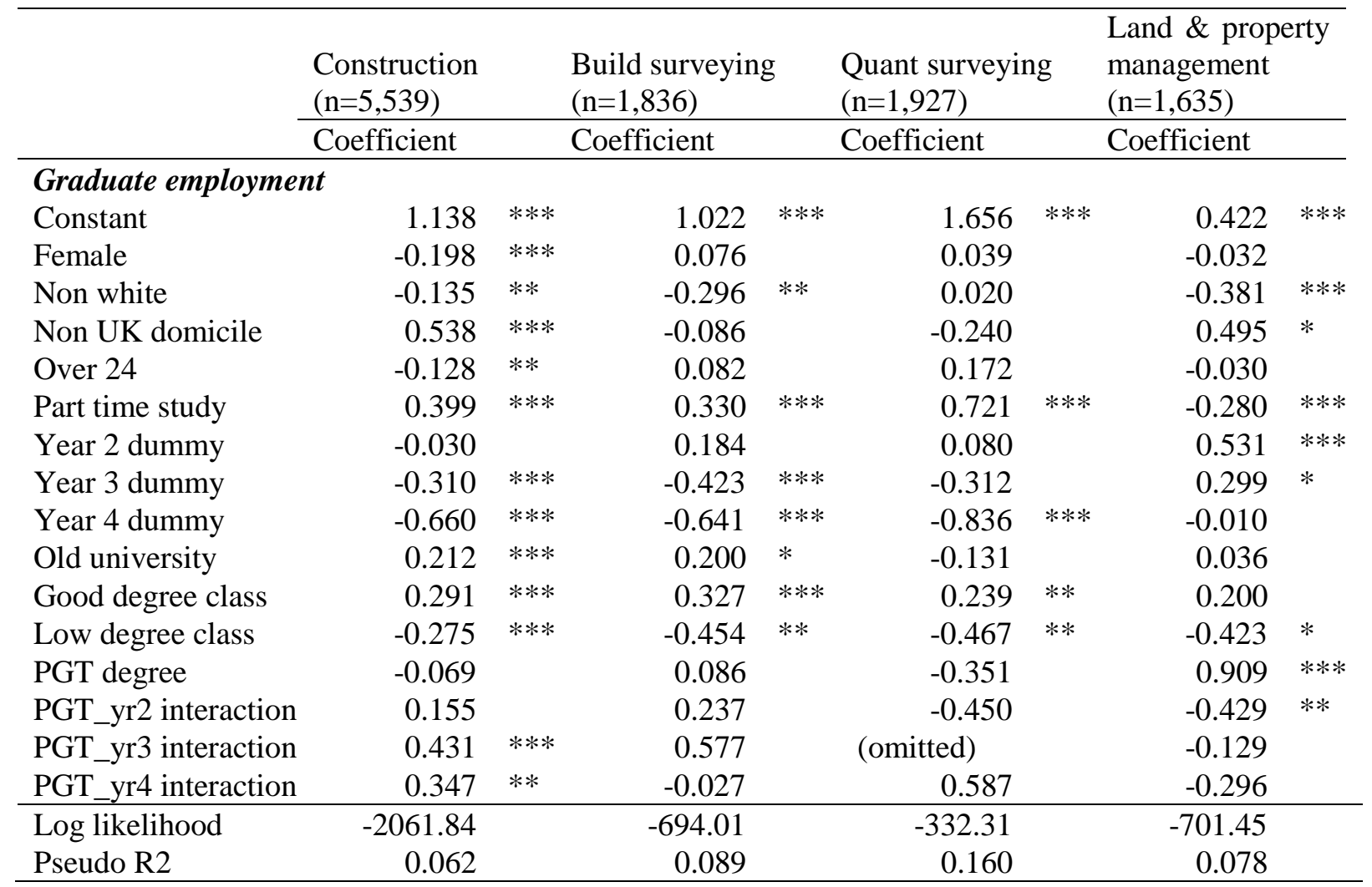

Notes: $* * *, * *$ and $*$ denote $1 \%, 5 \%$ and $10 \%$ significance levels, respectively. Omitted categories are white, under 24 , full time study, new university and graduating with a lower second class degree. 